\title{
VISUALISING USER EXPERIENCES: ANALYSING EMBODIMENT OF UX IN AUTONOMOUS VEHICLE CONCEPTS
}

\author{
Ranscombe, Charlie (1); Rodda, Jacob (1); Johnson, Mark (2) \\ 1: Swinburne University of Technology; 2: Ford Design
}

\begin{abstract}
The prospect of autonomous vehicles and associated technologies has disrupted traditional modes of vehicle operation and ownership. This requires automotive designers to shift their focus from designing vehicle form to consider the design of transport experiences. As such, there is a need to explore how best to support automotive designers in communicating user experiences (UX) alongside the physical design of vehicles. This paper presents an industry case study conducted with Ford Design Asia Pacific to assess the embodiment of UX in early concepts. Attributes of generalised model for UX are mapped to designers' storyboard illustration for the experience of an advanced concept for an autonomous vehicle interior. Results show how a mix of captions, sketches of users and contextual features illustrate different attributes of user experience. From findings we conclude firstly, the need to develop a toolkit to help designers communicate descriptions of as yet designed interactions. We also conclude that sketching contextual features of experience can provide a starting point to develop aspects of UX that can be used to differentiate and identify the Ford brand.
\end{abstract}

Keywords: Autonomous Vehicles, Case study, Conceptual design, Experience design, Visualisation

\section{Contact:}

Ranscombe, Charlie

Swinburne University of Technology

Architectural and Industrial Design

Australia

cranscombe@swin.edu.au

Cite this article: Ranscombe, C., Rodda, J., Johnson, M. (2019) 'Visualising User Experiences: Analysing Embodiment of UX in Autonomous Vehicle Concepts', in Proceedings of the 22nd International Conference on Engineering Design (ICED19), Delft, The Netherlands, 5-8 August 2019. DOI:10.1017/dsi.2019.411 


\section{INTRODUCTION}

The automotive industry is undergoing dramatic change. The prospect of autonomous vehicles and associated technologies has disrupted traditional modes of vehicle operation and ownership (Gowda et $a l ., 2014)$. The reduced focus on traditional vehicle ownership and the feasibility of sharing models of ownership has lead designers at Ford to shift their focus to consider the design of transport experiences, rather than simply vehicle's appearance and technical performance. As such user experience (UX) is of increasing value to automotive companies as a means to differentiate products and reinforce brand values (Gonzalez et al., 2018; Eckoldt et al., 2013).

The emergence of UX as a design discipline has coincided with the digital revolution and as such the majority of research in UX tools and methods has focused on digital products and interfaces (also described as Human Computer Interaction) (Unger 2012). Now as the importance of UX bleeds further into smart physical products (such as autonomous vehicles), the there is a need to understand and develop UX tools that are more clearly directed at 3d design instances (Law et al., 2014). For example, the shift toward UX means that advanced design teams comprised of designers highly skilled in the creation and communication of vehicle interiors and exteriors must now also visualise/communicate experience alongside the physical design elements (Michailidou et al., 2016). Yet, current UX tools provide little opportunity to envision and communicate $3 \mathrm{~d}$ design alongside stages of UX.

The end goal of research presented in this paper is to provide support for automotive designers in communicating experiences alongside the physical design of vehicles. Taking the first step to achieve this goal we conducted an industry case study with Ford Design's Asia Pacific Interiors team. We assess the embodiment of UX in early concepts by mapping attributes of generalised model for UX to designers' storyboard illustration envisioning the experience of an advanced concept for an autonomous vehicle interior. Doing so gives a preliminary overview as to how different attributes of experience are communicated, highlighting strategies currently used and any aspects of UX that are underrepresented. In terms of research contribution, this study demonstrates a method analyse visual and verbal content of storyboards with respect to UX theory to be refined and applied in further studies.

The paper first gives some background to the typical design activities in automotive design and UX design, followed by a brief review of key UX frameworks. Section 3 describes the method used to map storyboards with UX frameworks. Section 4 then describes results discussing where storyboards focus, and how designers can modify practice to consider a more comprehensive UX. Conclusions and implications for future design practices in advanced design are given in section 5.

\section{BACKGROUND}

\subsection{Practices in advanced automotive design}

Design studios (also known as advanced design teams) in the automotive sector are charged with envisioning vehicle and brand design direction 10-20 years into future. Traditionally these design teams are skilled in the design of the physical form of the vehicle both internally and externally, providing a vision for the brand's future offerings, and in doing so shaping the direction for engineering design teams. Typically, the tools used by advanced design teams are sketches, $3 \mathrm{~d}$ digital models, clay models (Tovey et al., 2003) and increasingly AR and VR. Unsurprisingly, the focus of these tools is in communicating $3 \mathrm{~d}$ form/geometry and not necessarily UX. One design tool that is being increasingly used by Ford design to break this trend and integrate communication of experience are storyboards. This is because they offer a mode of visual communication that can contextualise emergent designs in terms of user interaction and intended experience, far sooner, and without the investment of detailed VR or full-scale prototyping.

\subsection{Typical tools and techniques for designing user experience}

As stated above, the majority of research in the field of UX has focused on digital products and applications. In turn this has shaped the tools that designers in related industries commonly use. Task 
flows, storyboards, wireframes and prototypes are among the most common tools for communicating UX in the design of digital products (Unger 2012). Review of such tools shows their focus is on sequences, inputs and outputs while any visualisation of the product/artefact to achieve these occurs much later in the design process in the form of wireframes (to some extent) and prototypes. We note storyboards stand out as a widely used tool (Truong et al., 2006) and one which (ideally) include greater visualisation of experience (Buxton 2007; Marquardt and Greenberg 2015). Still, while storyboards are one of the most visually rich UX design tools, there is still substantial difference between typical UX storyboards and those used in automotive design. Namely, that $2 \mathrm{~d}$ digital products can be prototyped in greater detail and more quickly and cheaply, thus have less requirement to include visual information in a storyboard.

\subsection{Framework to describe user experience relevant in autonomous vehicle design}

Interest in UX from a range of design disciplines has led to the creation of a number of frameworks describing and generalising different attributes of UX. For the purpose of brevity, we focus this section on the literature synthesis presented in Lenz et al. (2014). This work surveys 19 prominent research papers across design disciplines to establish categories of experience and attributes within. The resulting framework presents a model for user experience consistent with key research in the field while also suitably generalised to be appropriate for the domain of automotive design.

The framework is split into two categories of experience attributes named Be-Level and Motor-Level. The Be-Level describes psychological attributes of experience considering the needs or motivations that contibute to users's experience while interacting with products. These attributes are considered in terms of seven different needs, Autonomy, Competence, Relatedness, Popularity, Stimulation, Security and Meaning. The Motor-Level describes the interactions required to achieve the functionality of the product (eg. operating controls). Interactions on this level are split into six categories, Temporal, Spatial, Action-Reaction, Presentation, Forces and Meta. Within the MotorLevel Lenz et al. (2013) propose an interaction vocabulary. This is a set of word pairs that can be used to describe experiences within the Motor-Level experience attributes, providing further detail to experiences envisioned. Table 1 gives a summary of the framework derived from Lenz et al. (2014) and Lenz et al. (2013) used as the basis for analysis in the remainder of the paper.

Table 1. Summary of attributes comprising the UX framework used to study automotive designers' storyboards

\begin{tabular}{|c|c|c|}
\hline Be-Level & Motor Level & Interaction Vocabulary \\
\hline - Autonomy & - Temporal & - Fast vs Slow \\
- Competence & - Spatial & - Stepwise vs Fluent \\
- Security & - Action- Reaction & - Instant vs Delayed \\
- Relatedness & - Presentation & - Uniform vs Diverging \\
- Popularity & - Forces & - Constant vs Inconstant \\
- Meaning & - Meta & - Mediated vs Direct \\
- Stimulation & & - Spatial Separation vs Spatial Proximity \\
& & - Approximate vs Precise \\
& & - Gentle vs Powerful \\
& & - Incidental vs Targeted \\
& & - Apparent vs Covered \\
\hline
\end{tabular}

\section{METHOD}

The focus of the study reported in this paper is a storyboard created by Ford Design team. The storyboard consists of 17 cells (frames) illustrating the experience of travelling in an autonomous vehicle from Paris to Cologne. Within this experience the different cells illustrate the various capabilities of the vehicle and its interactions with the driver (Stefan) and passenger (Anna). The storyboard is presented in the form of black and white sketches and captions giving further description of the experience as needed. A sample of cells are shown in Figure 1. 
The approach to analyse the storyboard is derived from Law et al. (2014). This based on their aim, to understand how abstract UX frameworks proposed in academic literature can inform practice, being closely aligned that of our study. In our study we map instances of the different attributes of UX framework detailed in section 2.3. This is achieved by coding each cell in the storyboard first for BeLevel attributes, then Motor-Level and finally for interaction vocabulary pairs. As such we can get an overview of which attributes are communicated in the storyboard and in turn can analyse how they are communicated.

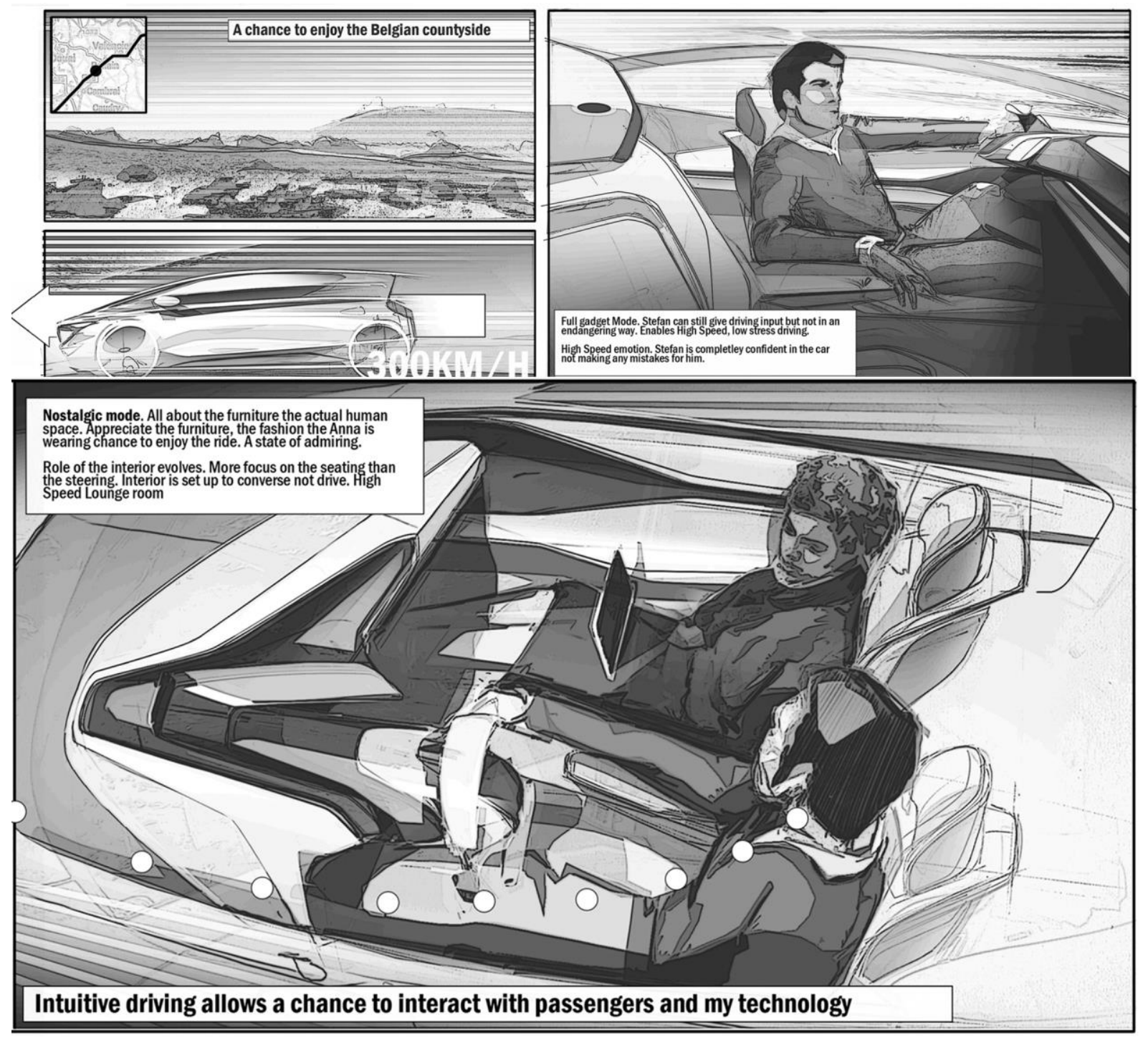

Figure 1. Examples of storyboard cells analysed

Criteria for coding is taken directly from definitions set out in Lenz et al. (2014) for Be-Level and MotorLevel, and Lenz et al. (2013) for vocabulary pairs. For captions coding is relatively straightforward. Key terms in captions are identified as being suitably similar in meaning to those given in attribute definitions. Coding the sketch component is less straightforward as identifying attributes is far more subjective. Our inductive coding approach used expert coders deemed to be suitably experienced in sketching/visual communication. Expertise was in the form of over 10 years of experience teaching Industrial Design in higher education, and 10 years of experience in automotive design respectively for the two coders. One iteration of coding was required to achieve a consensus between coders.

We now give an example of coding referring to Figure 1 top right cell. Text stating "Stefan can still give driving input" is coded as exemplifying Autonomy on the basis of Stefan's "input". The phrase "confident in the car not making any mistakes for him" is coded as communicating Competence. Referring to the sketch we can see how the designer has illustrated Stefan in a relaxed comfortable 
pose indicative of communicating Stimulation (at a low level). In terms of Motor-Level attributes the term "enables" indicates an Action and subsequent Reaction by the car. Similarly, the sketch showing Stefan's hand touching the console is indicative of Force applied to the console to achieve the action.

The number of occurrences of attributes is recorded however analysis is primarily qualitative investigating patterns in how attributes are manifested. Similarly, we do not attempt to quantify the extent to which a certain attribute is featured in each image as creating such a scale was deemed too subjective and beyond the scope of this study.

\section{RESULTS}

The mapping process provides an overview of number of cells in which attributes feature and respective modes of communication. Key trends in the way attributes of the UX are communicated in the storyboard are subsequently discussed for Be-Level and Motor level attributes.

Table 2. Overview of embodiment of Be-Level attributes in the storyboard

\begin{tabular}{|c|c|c|c|c|}
\hline $\begin{array}{l}\text { Be-level } \\
\text { Attributes }\end{array}$ & Definition & $\begin{array}{l}\text { No. } \\
\text { cells }\end{array}$ & Mode of communication & Example \\
\hline Autonomy & $\begin{array}{l}\text { Being the cause of } \\
\text { one's own actions }\end{array}$ & $9 / 17$ & $\begin{array}{l}\text { Through captions indicating } \\
\text { how the driver is able to have } \\
\text { involvement in controlling the } \\
\text { vehicle as it drives while also } \\
\text { indicating what different inputs } \\
\text { achieve. }\end{array}$ & $\begin{array}{l}\text { "Stefan is completely } \\
\text { confident in the car not } \\
\text { making mistakes for him" } \\
\text { Figure 1 (top right) }\end{array}$ \\
\hline Competence & $\begin{array}{l}\text { Being capable and } \\
\text { effective in your } \\
\text { actions }\end{array}$ & $10 / 17$ & $\begin{array}{l}\text { Through captions indicating } \\
\text { functionalities of the vehicle } \\
\text { and how this improves the } \\
\text { driver's capability as he controls } \\
\text { the vehicle }\end{array}$ & $\begin{array}{l}\text { "Reading traffic } \\
\text { conditions to help you } \\
\text { understand incoming } \\
\text { traffic conditions" }\end{array}$ \\
\hline Security & $\begin{array}{l}\text { Being in control of } \\
\text { one's } \\
\text { circumstances }\end{array}$ & $10 / 17$ & $\begin{array}{l}\text { Through captions stressing the } \\
\text { driver retains control of the } \\
\text { situation while relinquishing } \\
\text { some control to the vehicle. }\end{array}$ & $\begin{array}{l}\text { "Stefan can still give } \\
\text { driving input but not in an } \\
\text { endangering way" Figure } \\
1 \text { (top right) }\end{array}$ \\
\hline Relatedness & $\begin{array}{l}\text { Regular contact } \\
\text { with people who } \\
\text { care about you }\end{array}$ & $5 / 17$ & $\begin{array}{l}\text { Visually illustrating scenarios } \\
\text { within the car where Stefan and } \\
\text { Anna are conversing } \\
\text { supplemented with captions }\end{array}$ & $\begin{array}{l}\text { Figure } 1 \text { bottom, "a } \\
\text { chance to interact with } \\
\text { passengers and } \\
\text { technology" }\end{array}$ \\
\hline Popularity & $\begin{array}{l}\text { Being liked, } \\
\text { respected, and } \\
\text { having influence } \\
\text { over others }\end{array}$ & $6 / 17$ & $\begin{array}{l}\text { Visually implied through the } \\
\text { presence and relationship with } \\
\text { Anna. The use of the vehicle } \\
\text { having a positive effect on } \\
\text { social status is never directly } \\
\text { communicated through captions }\end{array}$ & $\begin{array}{l}\text { Figure } 1 \text { bottom illustrates } \\
\text { the relationship with } \\
\text { passenger featuring in } \\
\text { experience. }\end{array}$ \\
\hline Meaning & $\begin{array}{l}\text { Developing your } \\
\text { best potentials and } \\
\text { making life } \\
\text { meaningful }\end{array}$ & $7 / 17$ & $\begin{array}{l}\text { In captions Meaning is } \\
\text { communicated as goal } \\
\text { statements for how the vehicle } \\
\text { will influence the user. One } \\
\text { significant }\end{array}$ & $\begin{array}{l}\text { Visually in a sketch of } \\
\text { Stefan looking relaxed } \\
\text { and focused alongside the } \\
\text { statement "Technology } \\
\text { assists in [bringing] back } \\
\text { the purity of driving" }\end{array}$ \\
\hline Stimulation & $\begin{array}{l}\text { Experiencing } \\
\text { enjoyment and } \\
\text { pleasure as } \\
\text { opposed to } \\
\text { boredom }\end{array}$ & $7 / 17$ & $\begin{array}{l}\text { Some instances of explicit } \\
\text { verbal communication of } \\
\text { enjoyment otherwise } \\
\text { stimulation is communicated } \\
\text { visually in satisfied expressions } \\
\text { of Stefan }\end{array}$ & $\begin{array}{l}\text { Figure } 1 \text { top right "A } \\
\text { chance to enjoy the } \\
\text { Belgian countryside" }\end{array}$ \\
\hline
\end{tabular}




\subsection{Embodiment of be-level attributes}

Table 2 gives an overview of communication of Be-level attributes in the storyboard. Due to space restrictions, only cells 5, 6 and 15 are included within the paper (Figure 1 top right, top left and bottom respectively). Where possible examples refer to these images.

The three most frequently identified Be-Level attributes in the storyboard were Autonomy, Competence and Security. We contend these attributes are linked to key topics of debate with respect to future of autonomous vehicles so it is not a surprise that the author of the storyboard would focus or have some bias towards ensuring these are communicated to the reader. As shown in Table 2, many of these occurrences are communicated through captions rather than sketches. This highlights a trend in the way the design team are able to indicate some of the more pragmatic Be-Level attributes. Hence, while aspects of the physical form are ambiguous in sketches (I.e. specifics of the interface or options communicated to the driver), captions clearly communicate intentions and outcomes in describing the experience. Thus, in terms of designing a physical form we can see that the addition of captions help to explain the more pragmatic Be-Level attributes contextualise the physical design within the vision of the user experience.

Table 3. Overview of embodiment of Motor-Level attributes in the storyboard

\begin{tabular}{|c|c|c|c|c|}
\hline $\begin{array}{l}\text { Motor-level } \\
\text { Attributes }\end{array}$ & Definition & $\begin{array}{l}\text { No. } \\
\text { cells }\end{array}$ & Mode of communication & Example \\
\hline Temporal & $\begin{array}{l}\text { Duration of } \\
\text { interaction, } \\
\text { sequence of } \\
\text { interaction steps }\end{array}$ & $9 / 17$ & $\begin{array}{l}\text { A combination of illustrations and } \\
\text { captions. Interactions appear almost } \\
\text { instantaneous as little detail on } \\
\text { specific steps is included. }\end{array}$ & $\begin{array}{l}\text { "Automatically car } \\
\text { adjusts to the extra } \\
\text { needs for Anna." }\end{array}$ \\
\hline Spatial & $\begin{array}{l}\text { Use of space, } \\
\text { spatial distribution } \\
\text { of elements }\end{array}$ & $9 / 17$ & $\begin{array}{l}\text { Spatial elements are illustrated. This } \\
\text { is not surprising given the design } \\
\text { team's focus on interior design. }\end{array}$ & $\begin{array}{l}\text { Figure } 1 \text { top right and } \\
\text { bottom }\end{array}$ \\
\hline $\begin{array}{l}\text { Action - } \\
\text { Reaction }\end{array}$ & $\begin{array}{l}\text { Relation of action } \\
\text { to reaction, } \\
\text { feedback, or } \\
\text { response }\end{array}$ & $8 / 17$ & $\begin{array}{l}\text { Existence of actions and reactions is } \\
\text { implied. Captions indicate the } \\
\text { occurrence of an interaction, } \\
\text { illustrations show the result of the } \\
\text { subsequent reaction. }\end{array}$ & $\begin{array}{l}\text { Figure } 1 \text { top right } \\
\text { "Enables high speed } \\
\text { mode" }\end{array}$ \\
\hline Presentation & $\begin{array}{l}\text { Mode of presenting } \\
\text { information and } \\
\text { interaction } \\
\text { possibilities }\end{array}$ & $7 / 17$ & $\begin{array}{l}\text { Presentation is described on some } \\
\text { level in captions. There are no } \\
\text { illustrations of detailing presentation } \\
\text { of information to the user. }\end{array}$ & "Car informs...", \\
\hline Forces & $\begin{array}{l}\text { Force required for } \\
\text { a physical } \\
\text { interaction }\end{array}$ & $3 / 17$ & $\begin{array}{l}\text { Illustrated through driver's gestures } \\
\text { and hand movements with respect to } \\
\text { console and steering control }\end{array}$ & $\begin{array}{l}\text { Figure } 1 \text { top right and } \\
\text { bottom }\end{array}$ \\
\hline
\end{tabular}

The more subjective and introspective attributes of Be-level experience (Relatedness Popularity Meaning) are communicated less frequently than the aforementioned practical attributes, but nevertheless do feature. A trend in these attributes is that they are communicated through sketches more so than captions. Much of this communication is facilitated by the inclusion of sketches of the users, showing expressions and body language (for example Figure 1, top right). Sketching locations/scenes (Figure 1, top left) and activities the users engage in alongside the driving experience, for example showing Stefan and Anna enjoying coffee (image not included in this paper). We contend that such illustrations (as opposed to verbal descriptions) provide a richness of communication that helps to communicate these more subjective attributes of user experience. A further finding from this pattern relates the communication of Stimulation. We note some instances of stimulation also being communicated through expressions of the users. However, not all sketches of the users are illustrated in as much detail, thus at times stimulation is hard to discern. Hence a further reflection on the sketching of characters is that more detail in the illustration of facial expressions and body language can help to more comprehensively illustrate user stimulation as well as subjective attributes like Relatedness, Popularity and Meaning. 


\subsection{Embodiment of motor level attributes and interaction vocabulary}

Table 3 gives an overview of communication of Motor-level attributes (practical steps/interactions carried out by a user in order to achieve their goals) in the storyboard. Table 4 then provides detail on the communication of Interaction Vocabulary describing Motor-level attributes of experience.

In terms of representing a comprehensive experience, the storyboard clearly communicates a range of Motor-Level attributes but leaves gaps in giving descriptions (through interaction vocabulary). The overall impression of many Motor-Level attributes is of fast interactions requiring little input from the user to achieve desired outcomes. For example, Temporal attributes were interpreted as being Fast and Fluent. Similarly, Actions and Reactions are shown as being Instant and Mediated with the vehicle carrying out a series of complex steps leading to instantaneous response.

With respect to the Spatial attribute, the majority of the experience of the vehicle is coded as being in close proximity. This is because the user is illustrated within the vehicle for most interactions. The two exceptions relate to summoning the vehicle remotely via smartphone. We note that were more detail of the driver's interaction with certain interfaces presented, the assessment relative level of proximity may change. The same can be said for both Presentation and Forces.

Table 4. Overview of embodiment of Interaction Vocabulary communicated with respect to Motor-Level attributes in the storyboard

\begin{tabular}{|c|c|c|c|}
\hline $\begin{array}{l}\text { Interaction } \\
\text { Vocabulary }\end{array}$ & $\begin{array}{l}\text { Relates to } \\
\text { (Motor level) }\end{array}$ & Communication & Example \\
\hline $\begin{array}{l}\text { Fast }-8 \\
\text { Slow }-1\end{array}$ & Temporal & \multirow{2}{*}{$\begin{array}{l}\text { In the majority of cells input from the user is } \\
\text { met with an almost instant response from the } \\
\text { car. We note, the direct reference to time is } \\
\text { helpful in communicating the temporal } \\
\text { aspects of the experience on a macro level. } \\
\text { With respect to the more micro interactions, } \\
\text { fast and fluent aspects are implied by the } \\
\text { user's reaction. }\end{array}$} & $\begin{array}{l}\text { "Automatically the car } \\
\text { adjusts to Anna's needs" }\end{array}$ \\
\hline $\begin{array}{l}\text { Stepwise - } 0 \\
\text { Fluent - } 9\end{array}$ & Temporal & & $\begin{array}{l}\text { "Reading traffic } \\
\text { conditions to help you } \\
\text { understand incoming } \\
\text { traffic conditions" }\end{array}$ \\
\hline $\begin{array}{l}\text { Separation - } 2 \\
\text { Proximity - } 7\end{array}$ & Spatial & $\begin{array}{l}\text { The two Separate' interactions are illustrated } \\
\text { in steps showing Stefan summon the vehicle } \\
\text { through smartphone. The remainder of } \\
\text { interactions occur within the vehicle, hence } \\
\text { are deemed as close }\end{array}$ & $\begin{array}{l}\text { Figure } 1 \text { top right and } \\
\text { bottom }\end{array}$ \\
\hline $\begin{array}{l}\text { Instant - } 6 \\
\text { Delayed - } 0\end{array}$ & $\begin{array}{l}\text { Action - } \\
\text { Reaction }\end{array}$ & \multirow{2}{*}{$\begin{array}{l}\text { Reactions appear almost instantaneous. } \\
\text { Similarly steps to achieve a desired result are } \\
\text { heavily mediated. In other words, simple } \\
\text { inputs lead to car to completing relatively } \\
\text { complex sequence of steps. }\end{array}$} & \multirow{2}{*}{$\begin{array}{l}\text { “... highlights crazy } \\
\text { driver and car } \\
\text { intervenes" }\end{array}$} \\
\hline $\begin{array}{l}\text { Mediated - } 7 \\
\text { Direct - } 3\end{array}$ & $\begin{array}{l}\text { Action - } \\
\text { Reaction }\end{array}$ & & \\
\hline $\begin{array}{l}\text { Uniform - } 3 \\
\text { Diverging - } 0\end{array}$ & $\begin{array}{l}\text { Action - } \\
\text { Reaction }\end{array}$ & $\begin{array}{l}\text { Communicated in both illustrations and } \\
\text { captions showing the capacity of the vehicle } \\
\text { to make changes with a reliable outcome }\end{array}$ & $\begin{array}{l}\text { Shown in sketches of the } \\
\text { vehicle making } \\
\text { adjustments }\end{array}$ \\
\hline $\begin{array}{l}\text { Approximate } \\
-1 \\
\text { Precise }-7\end{array}$ & Presentation & $\begin{array}{l}\text { Presentation is simple and precise } \\
\text { information as information is rarely } \\
\text { ambiguous or provided as a list of } \\
\text { alternatives. }\end{array}$ & $\begin{array}{l}\text { "Car supplies city info, } \\
\text { hotel and restaurant } \\
\text { reservation" (note } \\
\text { presentation not } \\
\text { illustrated) }\end{array}$ \\
\hline $\begin{array}{l}\text { Gentle - } 3 \\
\text { Powerful - } 0\end{array}$ & Forces & $\begin{array}{l}\text { Forces are communicated through } \\
\text { illustrations of the driver showing relaxed } \\
\text { input, i.e. rarely requiring substantial force }\end{array}$ & $\begin{array}{l}\text { Figure } 1 \text { top right and } \\
\text { bottom }\end{array}$ \\
\hline
\end{tabular}


The question raised by these trends is whether the interpreted descriptions of Motor-Level attributes are the intention of the designer, or whether it is a symptom of the level detail in which the concept is illustrated? It may be that some attributes of the experience communicated are caused by the resolution of detail shown in sketches, and/or the way storyboard only represents discrete steps in in an interaction. It is likely that the design team do intend to illustrate a slick and seamless experience where the vehicle is highly capable requiring very little input from the driver. This being said, there is a strong likelihood that as details of the design evolve, so might the intricacy of interactions. As the intricacy of interactions evolve, so could the Motor-Level attributes of the experience, in turn having a dramatic effect on the resulting user experience. This is significant as the lack of specificity has a potential knock on effect as the to the direction in which teams responsible for creating technology that facilitates the experience envisioned in the storyboard and requisite $R \& D$ budget.

As such the analysis of embodiment of Motor-Level attributes highlights a kind of dichotomy in that advanced design teams create conceptual visions where many details are ambiguous as they are yet to be developed through further design. The consequence in communicating user experience is that some attributes of experience, specifically descriptions of Motor-Level attributes of experience, cannot be explicitly communicated through sketches.

\subsection{Suggestions for Advanced autonomous vehicle UX design}

Advanced design is highly conceptual in nature as at this stage design tends to be high level where many details are yet to be resolved. As highlighted above, this presents a barrier for designers to communicate details in Motor-Level attributes. An approach to solving or at least mitigating this can be drawn from communication of the more pragmatic Be-level attributes. In this category we see that captions play an important role in describing key functionality that isn't readily represented or interpreted from sketches. In reference to Motor level interactions we suggest drawing on the analytical approach of (Lenz et al., 2013) to verbally code descriptions of the interaction. For example, Figure 1 (top right) shows enabling of high speed mode could be accompanied by keywords describing the Action- Reaction and Force attributes. As such the design team can envision the intended experience in a manner that provides more detail for future design work. Naturally design is always iterative and some elements may change, however the more information communicated, the greater the reflection on the potential merit of a given design can occur prior to investment in expensive prototypes.

In consideration of industry desire to differentiate and add value through user experience, the storyboard shows some promising examples of the way designers are already considering less tangible, introspective Be-Level attributes. Relatedness, Popularity and Meaning are contended to be attributes of experience less influenced by design resolution (communicated) and hence well suited to advanced design activities. With respect to adding value/differentiation, these attributes are particularly relevant as they are closely connected with manifestation brand, a priority in automotive design (Ranscombe et al., 2012). Hence continuing to include and develop these elements can be helpful in growing the connection between brand identity and UX. Furthermore, establishing such descriptions gives the design team an opportunity to envision/define attributes of experiences that can be applied consistently across the brand's product offering as they are not yet tied to precise functional interactions. Hence, we can see how developing subjective/introspective attributes of experience can provide a platform to establish consistent branded experience and the basis for differentiation through user experience.

One important implication of designing contextual elements of the experience is that designers will be moving even further from the design and communication form and physicality needing engage in even deeper consideration of the user, and their response. From this case study we can identify that inclusion of these aspects shows this type of design activity is within the designer's capability. However, in terms of resources, the complexity that designing a vehicle involves is unchanged thus so deviating will naturally impact on resources. 


\subsection{Limitations and further work}

Given the case study nature of this research there are naturally limitations to the extent to which we can conclude on universal best practice across the industry. A more comprehensive study analysing a greater sample of storyboards, covering different concepts and driving scenarios, and created at different stages of the design process (hence with less ambiguity), would provide more generalisable conclusions on how UX can best be illustrated alongside visualisations of forms. Similarly, there are limitations in terms of validating our method to analyse storyboards. A more comprehensive study would also provide validation of our research method to analyse storyboards.

With respect to the practices of designers, we suggest the inclusion of interaction vocabulary in captions could help to give greater resolution to experience while sketches of forms are still somewhat ambiguous. An immediate topic of further research for the Ford team would be the creation of a toolkit/guide as to how this could be implemented also studying how other stakeholders in the design process respond to such communications. Our findings also highlight the opportunity for designers to use certain Be-Level attributes of experience with brand. Further research would be required to understand which of these attributes connect to Ford's brand values but also how they could influence brand identification.

\section{CONCLUSION}

The prospect of autonomous vehicles has led to major changes in the way automotive design teams conceptualise new or advanced vehicles. This paper presents an industry case study with Ford Design Asia Pacific investigating the way their design teams communicate user experience alongside the physical design of vehicle interiors. A storyboard created by the interior design team to communicate a vision of future driving experiences was analysed to understand the embodiment of UX. This was achieved by mapping attributes from a generalised theoretical model of experience derived from academic research in UX to the sketches and captions that comprise the storyboard.

The analysis highlighted, how designers rely heavily on verbal captions in the storyboard to communicate the more pragmatic/functional Be-Level attributes of experience. Conversely the more subjective or introspective attributes of Be-Level experience are primarily communicated through sketches of users, landscapes, locations and activities. We highlight these rich communications as a strength to pursue in consideration of Ford wishing to create designs that differentiate from competition on the basis of UX. With respect to the embodiment of Motor-Level attributes of experience, analysis showed how the presence of interactions is well communicated through sketches and captions. However, more specific descriptions of such interactions were difficult to identify in the storyboard due to the ambiguity in sketches that result from designs being highly conceptual. Based on trends in Be-Level attributes we concluded that this issue can potentially be resolved by referencing interaction vocabulary pairs within the storyboard along with captions. Development of such a toolkit to employ descriptors in storyboards, along with research to better understand the relationship between subjective Be-Level attributes to brand identity form immediate further work that will help support automotive designers to consider UX alongside the design of physical forms.

\section{REFERENCES}

Buxton, B. (2007), Sketching user experiences: getting the design right and the right design, Morgan Kaufmann, San Francisco.

Eckoldt, K., Hassenzahl, M., Laschke, M. and Knobel, M. (2013), “Alternatives: exploring the car's design space from an experience-oriented perspective", Proceedings of the 6th International Conference on Designing Pleasurable Products and Interfaces, ACM, pp. 156-164.

Gonzalez, I., Val, E., Justel, D., Iriarte, I. and Lasa, G. (2018), “Aesthetic Interaction Consistency: Exploring the Foundation for Static and Dynamic Aesthetics”, Proceedings of the DESIGN 2018 15th International Design Conference, pp. 2209-2220.

Gowda, N., Ju, W. and Kohler, K. (2014), “Dashboard Design for an Autonomous Car", Adjunct Proceedings of the 6th International Conference on Automotive User Interfaces and Interactive Vehicular Applications, ACM, pp. 1-4. 
Law, E.L.-C., Hassenzahl, M., Karapanos, E., Obrist, M. and Roto, V. (2014), “Tracing links between UX frameworks and design practices: dual carriageway", Proceedings of HCI Korea, Hanbit Media, Inc., pp. $188-195$.

Lenz, E., Diefenbach, S. and Hassenzahl, M. (2013), "Exploring relationships between interaction attributes and experience", Proceedings of the 6th International Conference on Designing Pleasurable Products and Interfaces, ACM, pp. 126-135.

Lenz, E., Diefenbach, S. and Hassenzahl, M. (2014), “Aesthetics of interaction: a literature synthesis", Proceedings of the 8th Nordic Conference on Human-Computer Interaction: Fun, Fast, Foundational, ACM, pp. 628-637.

Marquardt, N. and Greenberg, S. (2015), "Sketching User Experiences: The Hands-on Course", Proceedings of the 33rd Annual ACM Conference Extended Abstracts on Human Factors in Computing Systems, ACM, pp. 2479-2480.

Michailidou, I., Franzen, F. and Lindemann, U. (2016), "Method to create market-specific customer profiles for enhancing positive user experiences in cars", 14th International Design Conference, pp. 1763-1772.

Ranscombe, C., Hicks, B. and Mullineux, G. (2012), “A method for exploring similarities and visual references to brand in the appearance of mature mass-market products", Design Studies, Vol. 33 No. 5.

Tovey, M., Porter, S. and Newman, R. (2003), "Sketching, concept development and automotive design", Design Studies, Vol. 24 No. 2, pp. 135-153.

Truong, K.N., Hayes, G.R. and Abowd, G.D. (2006), "Storyboarding: an empirical determination of best practices and effective guidelines", Proceedings of the 6th conference on Designing Interactive systems.

Unger, R. (2012) A project guide to UX design: for user experience designers in the field or in the making, 2nd edition. Pearson Education distribution. 